CLINICAL STUDY

\title{
Mass screening of newborns for congenital hypothyroidism of central origin by free thyroxine measurement of blood samples on filter paper
}

\author{
Masanori Adachi $^{1,2}$, Akiko Soneda ${ }^{1}$, Yumi Asakura ${ }^{1}$, Koji Muroya ${ }^{1}$, Yuji Yamagami ${ }^{2,3}$ and Fumiki Hirahara ${ }^{2,4}$ \\ ${ }^{1}$ Department of Endocrinology and Metabolism, Kanagawa Children's Medical Center, Mutsukawa 2-138-4, Minami-ku, Yokohama 232-8555, Japan, \\ ${ }^{2}$ Neonatal Mass-screening Committee, Kanagawa Prefecture Medical Association, Yokohama, Japan, ${ }^{3}$ Kanagawa Health Service Association, Yokohama, \\ Japan and ${ }^{4}$ Department of Obstetrics and Gynecology, Yokohama City University School of Medicine, Yokohama, Japan \\ (Correspondence should be addressed to M Adachi at Department of Endocrinology and Metabolism, Kanagawa Children's Medical Center; \\ Email: madachi@mars.sannet.ne.jp)
}

\begin{abstract}
Objective: To evaluate the effectiveness of mass screening of newborns for congenital hypothyroidism of central origin $(\mathrm{CH}-\mathrm{C})$ by measurement of free thyroxine $\left(\mathrm{FT}_{4}\right)$ and thyroid-stimulating hormone (TSH). Design: Questionnaire-based survey of $\mathrm{CH}-\mathrm{C}$ patients born between 1999 and 2008 in Kanagawa prefecture, Japan.

Methods: TSH and $\mathrm{FT}_{4}$ levels in dried blood spots on filter paper were measured using ELISA kits, and $\mathrm{CH}-\mathrm{C}$ was diagnosed at $\mathrm{FT}_{4}$ levels below a cutoff of $0.7 \mathrm{ng} / \mathrm{dl}(9.0 \mathrm{pmol} / \mathrm{l})$. Survey results were collated with the database created by the screening organizer.

Results: Twenty-four $\mathrm{CH}-\mathrm{C}$ patients (18 males) were identified, 14 of whom had multiple pituitary hormone deficiencies (group M), eight had isolated $\mathrm{CH}-\mathrm{C}$ (group I), and two had undetermined pituitary involvement (group U). In groups $\mathrm{M}, \mathrm{I}$, and $\mathrm{U}$, the number of patients with $\mathrm{FT}_{4}$ levels below the cutoff value at screening was five (36\%), seven (88\%), and one (50\%) respectively; other patients had been diagnosed clinically. Thus, 13 patients were true positives, while nine were false negatives, yielding screening sensitivity of $59.1 \%$ and positive predictive value of $11.5 \%$. The calculated sensitivity was $81.8 \%$ at a higher cutoff value of $0.9 \mathrm{ng} / \mathrm{dl}(11.6 \mathrm{pmol} / \mathrm{l})$. The overall incidence of $\mathrm{CH}-\mathrm{C}$ was estimated at 1 in 30833 live births, while that of $\mathrm{CH}$ of thyroidal origin $(\mathrm{CH}-\mathrm{T})$ is 1 in 3472 live births in Kanagawa prefecture (CH-T/CH-C, 8.9).

Conclusions: Newborn screening with combined $\mathrm{FT}_{4}$ and TSH measurements can identify a significant number of $\mathrm{CH}-\mathrm{C}$ patients before manifestation of clinical symptoms, but a more appropriate $\mathrm{FT}_{4}$ cutoff value should be considered.
\end{abstract}

European Journal of Endocrinology 166 829-838

\section{Introduction}

Screening of newborns for congenital hypothyroidism $(\mathrm{CH})$ is now routinely used in most of the developed world and in an increasing number of developing countries, which has prevented serious intellectual sequelae in a considerable number of patients with $\mathrm{CH}$ $(1,2)$. While most $\mathrm{CH}$ cases are due to $\mathrm{CH}$ of thyroidal origin (CH-T) manifesting as thyroid dysgenesis or thyroid hormone synthesis defects, a significant number of $\mathrm{CH}$ cases are due to inadequate thyroid-stimulating hormone (TSH) secretion from the anterior pituitary ( 3 , $4,5,6,7,8,9)$. The latter category of $\mathrm{CH}$ cases is termed as $\mathrm{CH}$ of central origin $(\mathrm{CH}-\mathrm{C})$. The incidence of $\mathrm{CH}-\mathrm{C}$ is estimated to be $\sim 1$ in 20 000-30 000 live births (3, 5, $6,7,10$ ), which is much higher than previously thought. Nevertheless, $\mathrm{CH}$ screening in Japan is mainly based on the detection of elevated TSH levels in dried blood samples on filter paper (primary TSH strategy). This assay has demonstrated high sensitivity in detecting $\mathrm{CH}-\mathrm{T}(11,12)$ but failed to identify newborns with $\mathrm{CH}-\mathrm{C}$. On the other hand, screening based on the detection of low $\mathrm{T}_{4}$ levels (primary $\mathrm{T}_{4}$ strategy) can identify CH-C newborns only inefficiently, as falsepositive cases are inevitable due to both thyroxinebinding globulin (TBG) deficiency and transient low $\mathrm{T}_{4}$ levels in critically ill newborns.

To overcome this situation, The Netherlands has implemented a system of assaying TSH, $\mathrm{T}_{4}$, and TBG, which can eliminate false-positive results caused by TBG deficiency $(5,6)$. Assaying free $\mathrm{T}_{4}\left(\mathrm{FT}_{4}\right)$ may be an alternative solution because $\mathrm{FT}_{4}$ is less influenced by TBG than $\mathrm{T}_{4}$. Moreover, determination of $\mathrm{FT}_{4}$ seems to be superior to that of $\mathrm{T}_{4}$ because this reduces falsepositive cases in premature newborns, according to the report of a smaller difference between full-term and 
preterm newborns in $\mathrm{FT}_{4}$ levels than in $\mathrm{T}_{4}$ levels measured in dried blood samples on filter paper (13). Therefore, in Kanagawa prefecture, we have adopted a strategy of simultaneously measuring $\mathrm{TSH}$ and $\mathrm{FT}_{4}$ in all newborns using a filter paper assay (9). Sapporo city has also adopted the same screening system. The report of a 5-year audit in Sapporo city was released in 2004, in which six $\mathrm{CH}-\mathrm{C}$ cases were identified through this screening (7). However, the study in Sapporo included only patients showing positive screening results, which preclude evaluation of the sensitivity of screening in detecting $\mathrm{CH}-\mathrm{C}$. In addition, the annual birth rate in Sapporo is approximately one-fourth of Kanagawa prefecture.

To evaluate the effectiveness of our $\mathrm{CH}-\mathrm{C}$ screening system, we have conducted a detailed, comprehensive survey of $\mathrm{CH}-\mathrm{C}$ patients from Kanagawa region, Japan. In this study, all $\mathrm{CH}-\mathrm{C}$ cases detected via screening and diagnosed clinically were included and used to estimate the sensitivity and positive predictive value (PPV) of the screening method.

\section{Subjects and methods}

\section{Outline of newborn screening system}

Kanagawa prefecture, in which Yokohama is the main city, is located in the central region of the Japanese islands, neighboring the Tokyo metropolitan area. The annual number of births in Kanagawa prefecture has been $\sim 70000$ in recent years. The incidence of $\mathrm{CH}-\mathrm{T}$ in Kanagawa prefecture is estimated to be 1 in 3472 births. Neonatal screening is exclusively conducted by the Neonatal Mass-screening Committee (NMC) of the Kanagawa Prefecture Medical Association (KPMA), which comprises executive officers, technical experts, gynecologists, general pediatricians, and pediatric endocrinologists. The screening procedure adopted by the NMC-KPMA is based on the determination of TSH and $\mathrm{FT}_{4}$ in dried blood spots on filter paper obtained 4 to 7 days after birth (median sampling day was the fifth day). According to the standard practice followed, newborns with high TSH levels $(\geq 30 \mu \mathrm{IU} / \mathrm{ml}$ serum) are immediately sent to one of the several pediatric endocrine units within the prefecture. A second filter paper sampling is requested for those with borderline TSH levels $\left(15-30 \mu \mathrm{IU} / \mathrm{ml}\right.$ serum) or low $\mathrm{FT}_{4}$ levels $(<0.7 \mathrm{ng} / \mathrm{dl}$ of serum $(9.0 \mathrm{pmol} / \mathrm{l}))$. If the results again indicate borderline $\mathrm{TSH}$ or low $\mathrm{FT}_{4}$, the baby is sent for a thorough evaluation. Thus, $\mathrm{CH}-\mathrm{C}$ is suspected if $\mathrm{FT}_{4}$ levels are low in two consecutive samples. To eliminate cases with transient low $\mathrm{FT}_{4}$ due to prematurity, samples taken from the newborns with birth weight $<2000 \mathrm{~g}$ are considered to be preliminary, and the results are sent to each attending physician as an unofficial report. Once the baby attains a weight of
$2500 \mathrm{~g}$ or reaches 30 days of age, the first sample is requested.

TSH levels in filter paper samples were determined by ELISA using mouse monoclonal antihuman TSH antibodies (Eiken Chemical Co. Ltd., Tochigi, Japan). To determine $\mathrm{FT}_{4}$ levels in filter paper samples, ENZAPLATE ${\mathrm{N}-\mathrm{FT}_{4}}_{4}$ was used (Siemens Healthcare Diagnostics K.K., Tokyo, Japan), which is an ELISA kit based on a competitive reaction between sample $\mathrm{FT}_{4}$ and peroxidase-tagged human $\mathrm{T}_{4}$ to bind to rabbit polyclonal antihuman $\mathrm{T}_{4}$ antibody (first antibody). A $3 \mathrm{~mm}$ disc is punched out from the filter paper and is incubated with peroxidase-tagged $\mathrm{T}_{4}$ and the first antibody in a reaction mixture of $150 \mu \mathrm{l}$ for $4 \mathrm{~h}$ at 18$25^{\circ} \mathrm{C}$ in a micro-well plate with immobilized caprine antirabbit IgG antibodies (second antibody). After removal of the filter paper disc and washing five times, $O$-phenylenediamine is added, and the absorbance is then measured at $492 \mathrm{~nm}$. A calibration curve is established using standard filter paper samples of known $\mathrm{FT}_{4}$ concentrations, which are provided by the manufacturer. $\mathrm{FT}_{4}$ level in the sample is then determined by comparison with the calibration curve.

The performance of this kit, of which there is only one study, reported in a Japanese journal (14), is as follows. The $\mathrm{FT}_{4}$ determination range is $0.5-5.0 \mathrm{ng} / \mathrm{dl}$, which is based on a precision level lower than $15 \%$ of the coefficient of variation $(\mathrm{CV})$. Intra-assay $\mathrm{CV}$ is $7.6-$ $15.0 \%$, whereas inter-assay $\mathrm{CV}$ is $9.4-18.5 \%$. The correlation between the $\mathrm{FT}_{4}$ levels measured by this kit and the electrochemiluminescence immunoassay (ECLIA) kit (Elecsys $\mathrm{FT}_{4}$; Roche Diagnostics) is shown in Fig. 1.

\section{Preliminary survey}

A preliminary survey was conducted in December 2008. Questionnaires were sent to all 139 hospitals with a pediatric section in Kanagawa prefecture. The questionnaire included questions about the number of $\mathrm{CH}-\mathrm{C}$ patients born in Kanagawa prefecture between January 1999 and December 2008 and treated continuously with levothyroxine $\left(\mathrm{L}-\mathrm{T}_{4}\right)$. $\mathrm{CH}-\mathrm{C}$ was defined as $\mathrm{CH}$ considered to be of hypothalamic or pituitary origin, excluding acquired sequelae of head trauma, brain tumor, etc., and irrespective of involvement of other pituitary functions. Cases of hypothyroxinemia due to prematurity were excluded.

\section{Secondary survey}

In April 2009, we requested the corresponding doctors caring for the probable $\mathrm{CH}-\mathrm{C}$ patients identified in the preliminary survey to provide detailed information, including patient profile, medical complications, data on newborn screening, and results of thyroid function, thyroid imaging studies, and pituitary function tests with imaging information. 


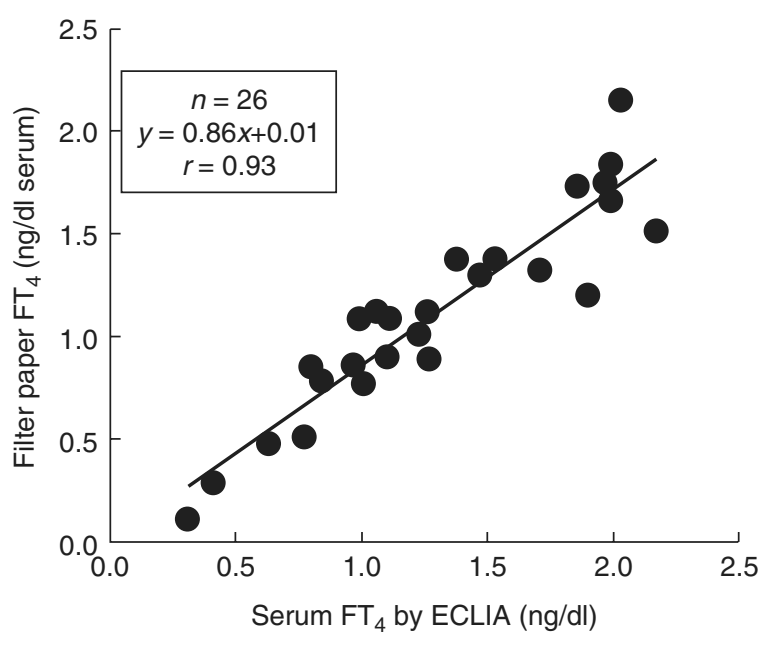

Figure 1 Correlation between $\mathrm{FT}_{4}$ levels in dried blood samples on filter paper measured by ELISA and $\mathrm{FT}_{4}$ serum levels measured by ECLIA for newborns and young infants. Filter paper blood specimens and serum samples were collected simultaneously from 26 infants younger than 2 months. $\mathrm{FT}_{4}$ levels of blood samples on the filter paper were measured by an ELISA kit, whereas serum $\mathrm{FT}_{4}$ was measured by ECLIA.

\section{Collation study}

After completion of the secondary survey, we collated the list of $\mathrm{CH}-\mathrm{C}$ patients identified through the above surveys with the NMC-KPMA database, in which information from the first-line investigation at the pediatric endocrine unit and the screening results for all patients with positive screening results had been compiled.

\section{Patient categorization}

CH-C patients identified through the secondary survey and collation study were categorized into three groups according to the involvement of other pituitary hormones. Group M comprised $\mathrm{CH}-\mathrm{C}$ patients with at least one pituitary hormone deficiency other than insufficient TSH secretion. These patients were considered to have congenital hypopituitarism with multiple pituitary hormone deficiencies. The diagnosis of each pituitary hormone deficiency was based on the attending physician's evaluation, except for GH deficiency, which was verified by at least one pharmacological stimulation test. Group I comprised isolated $\mathrm{CH}-\mathrm{C}$ patients without pituitary involvement other than TSH insufficiency. Group U consisted of $\mathrm{CH}-\mathrm{C}$ patients for whom pituitary involvement was undetermined.

\section{Statistical analysis}

Statistical analysis was carried out using Microsoft Office Excel 2007 (Microsoft Corporation). Correlation between the assay results of $\mathrm{FT}_{4}$ (ELISA) in filter paper samples and serum $\mathrm{FT}_{4}$ (ECLIA) was evaluated by linear regression analysis. Mann-Whitney U-test was used to compare $\mathrm{FT}_{4}$ values between groups M and I. Fisher's exact probability test was used to compare the incidence of screening positive patients according to the etiological categories (groups M and I). $P$ values of $<0.05$ were considered to be significant.

The Ethics Committee of Kanagawa Children's Medical Center reviewed and approved the study procedures.

\section{Results}

Out of the 139 hospitals from Kanagawa prefecture to which the preliminary survey questionnaire was sent, responses were obtained from 94 hospitals, including 14 hospitals stating that they currently had no pediatric section. Accordingly, the actual response rate was calculated to be $64.0 \%$ (80/125 hospitals with pediatric sections). Through this primary survey, 42 patients with probable $\mathrm{CH}-\mathrm{C}$ (2-11 years old) were identified at 14 out of the 80 hospitals.

Figure 2 shows the number of $\mathrm{CH}-\mathrm{C}$ patients, both probable and confirmed, identified through the surveys. The preliminary survey identified 42 probable patients, of which 20 patients were considered to represent true $\mathrm{CH}-\mathrm{C}$ cases. After collation with the NMC-KPMA database, $24 \mathrm{CH}-\mathrm{C}$ patients (of which 18 were male) were finally identified. Details of each patient are summarized in Tables 1 and 2. As the total number of newborns screened during the study period was 740003 , we calculated the minimal incidence of

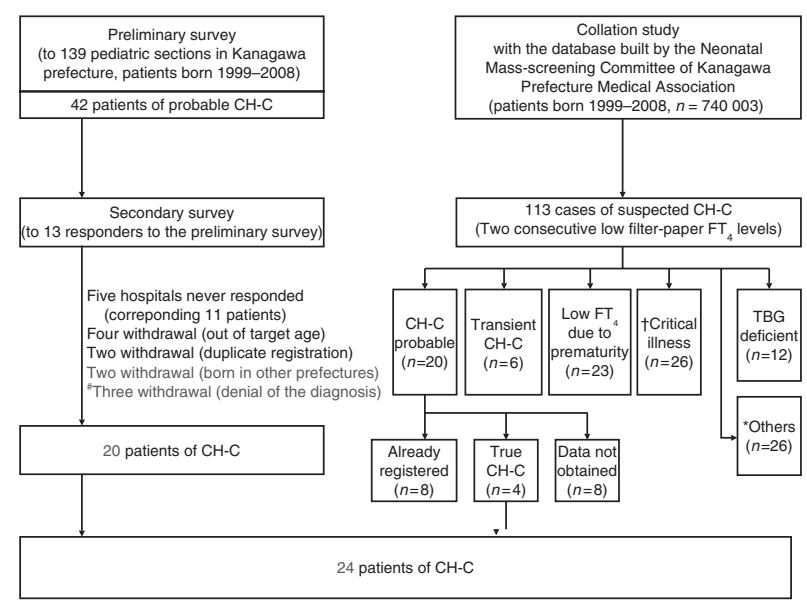

Figure 2 Overview of the study. "Three patients were excluded because they were judged not to have $\mathrm{CH}-\mathrm{C}$. Of these, two patients were diagnosed with $\mathrm{CH}-\mathrm{T}$ with delayed TSH elevation, while the third patient had transient low $\mathrm{FT}_{4}$, possibly because of an emotional deprivation syndrome. IIncluding one newborn with hydranencephaly. *Patients from whom we could not obtain detailed information. 


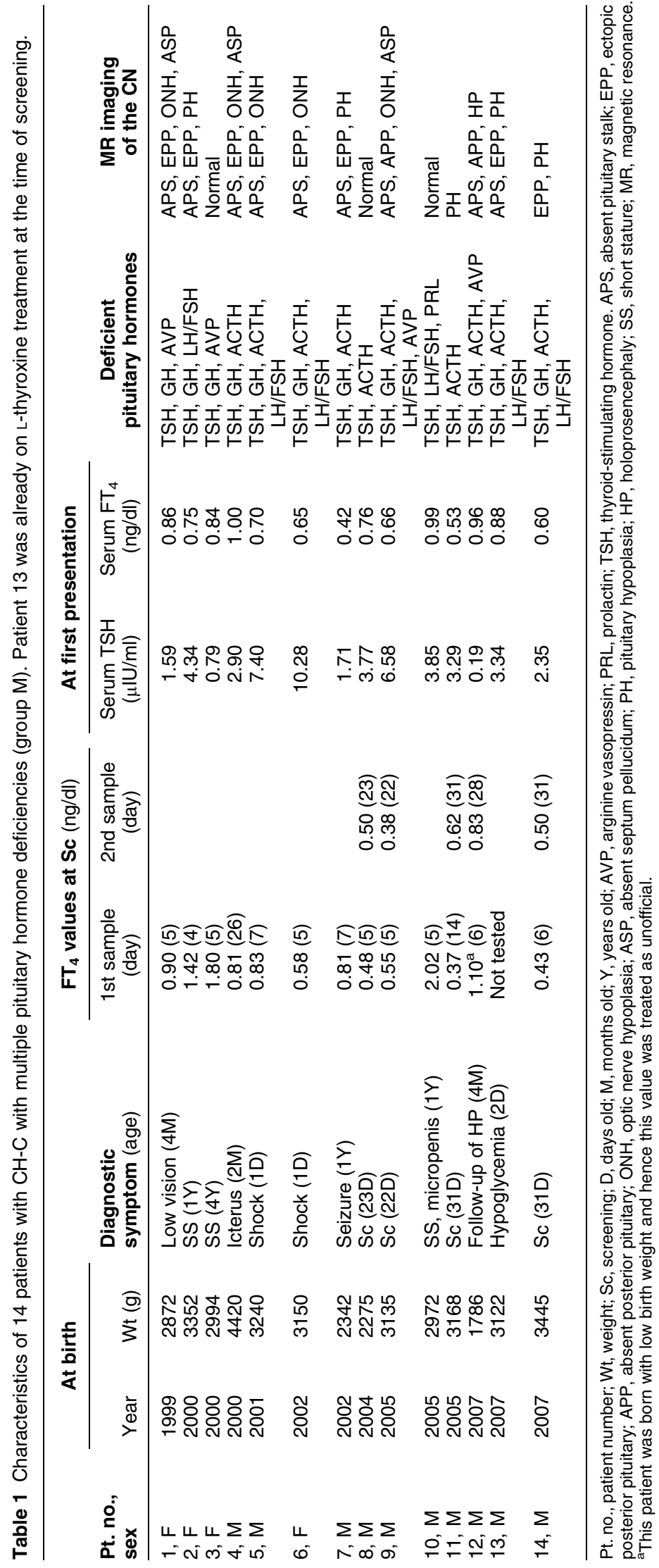




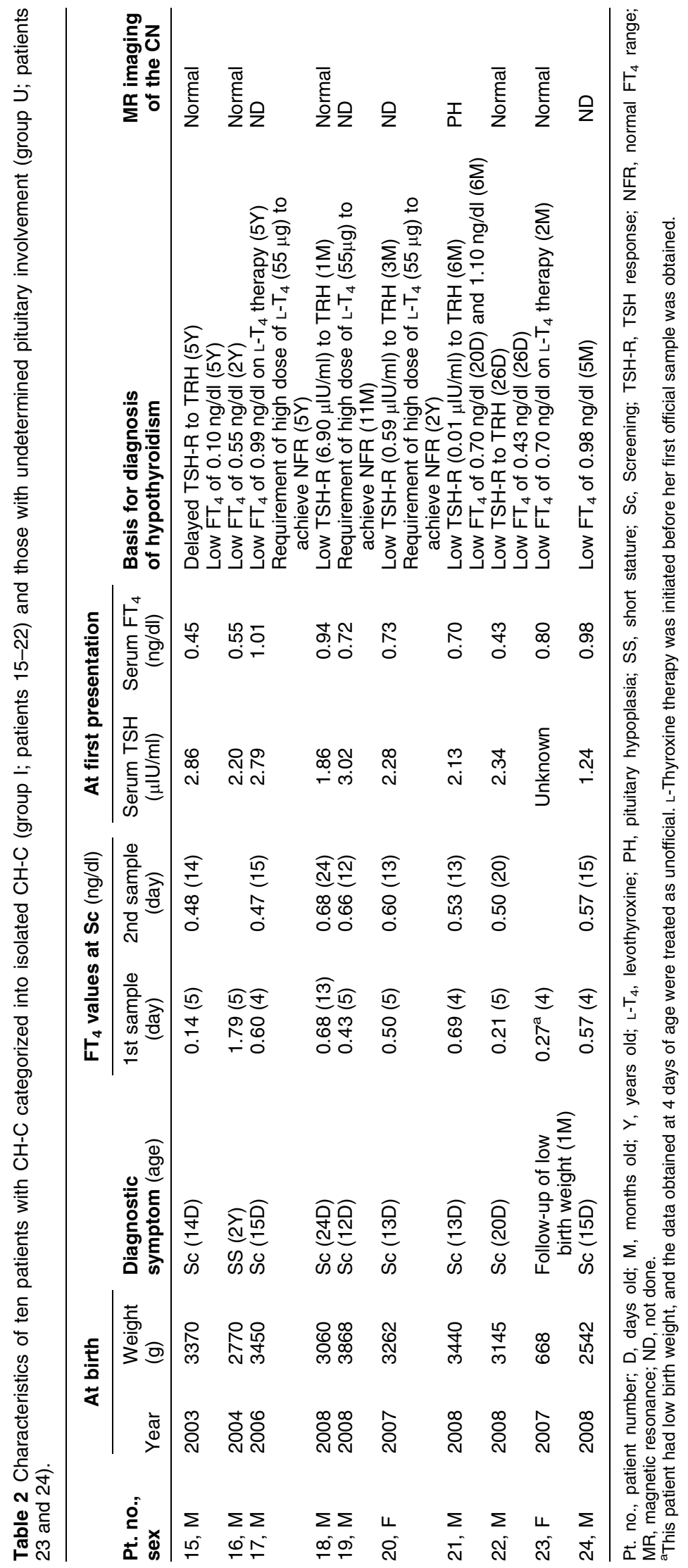


$\mathrm{CH}-\mathrm{C}$ in Kanagawa prefecture as 1 in 30833 births (24/740 003).

Among the 24 patients, 14 patients (58\%, ten males) were categorized into group $M$ (Fig. 3). Group M $(n=14)$ consisted of five patients with septo-optic dysplasia, five patients with pituitary hypoplasia, one with holoprosencephaly, and three with normal pituitary morphology. Eight other patients out of the 24 (33\%) were considered to have isolated $\mathrm{CH}-\mathrm{C}$, without pituitary involvement, and they were hence categorized as group I (Fig. 3). Pituitary function in the remaining two patients could not be fully evaluated because of their younger age, and they were therefore categorized as group U (Fig. 3).

Twelve patients (50\%) were identified as having $\mathrm{CH}-\mathrm{C}$ solely via the newborn screening system in Kanagawa prefecture (Fig. 3). Of these, four patients belonged to group $M$, seven patients to group I, and one patient to group U. In addition, patient 6 in group M was clinically diagnosed with $\mathrm{CH}-\mathrm{C}$ because this patient exhibited shock; however, the screening result was actually positive (low $\mathrm{FT}_{4}$ levels), and hence, this was considered as a true-positive case of $\mathrm{CH}-\mathrm{C}$. Therefore, the total number of true-positive $\mathrm{CH}-\mathrm{C}$ cases was 13 . In contrast, nine other patients out of 24 (38\%, eight patients in

\begin{tabular}{|c|c|c|c|}
\hline & $\begin{array}{c}\text { Multiple pituitary } \\
\text { hormone deficiencies } \\
\text { (group M) }\end{array}$ & $\begin{array}{c}\text { Isolated hypothyroidism } \\
\text { (group I) }\end{array}$ & $\begin{array}{c}\text { Undetermined } \\
\text { (group U) }\end{array}$ \\
\hline $\begin{array}{c}\text { Symptom-based } \\
\text { diagnosis } \\
(n=10)\end{array}$ \\
\hline $\begin{array}{c}\text { Screening-based } \\
\text { diagnosis } \\
(n=12)\end{array}$
\end{tabular}

Figure 3 Summary of the 24 patients with $\mathrm{CH}-\mathrm{C}$, categorized by presence/absence of other pituitary hormone deficiencies and diagnostic symptoms. The red and blue figures indicate female and male patients respectively. Figures within a single-line box indicate $\mathrm{CH}-\mathrm{C}$ patients who could have been identified as having $\mathrm{CH}-\mathrm{C}$ by screening if the $\mathrm{FT}_{4}$ cutoff values were $0.9 \mathrm{ng} / \mathrm{dl}$. The figure within a double-line box indicates the patient diagnosed with septo-optic dysplasia presenting with shock, who had $\mathrm{FT}_{4}$ levels $<0.7 \mathrm{ng} / \mathrm{dl}$ according to the results of the filter paper assay. ${ }^{\mathrm{F} T} \mathrm{~F}_{4}$ data with the filter paper assay were not available for two patients; L-thyroxine treatment was initiated in one male patient at 2 days of age. One female patient had low birth weight, and the data obtained at 4 days of age were treated as unofficial. L-Thyroxine therapy was initiated before the first official sample was obtained from this patient. group $\mathrm{M}$ and one in group I) had normal screening results and were revealed to have $\mathrm{CH}-\mathrm{C}$ through the evaluation of clinical symptoms such as shock and/or hypoglycemia during the neonatal period $(n=2)$, short stature $(n=4)$, and other features $(n=3)$. These nine patients were considered to be false negatives. The remaining two patients (one in group $\mathrm{M}$ and one in group U, depicted as '?' in Fig. 3) were already on $\mathrm{L}^{-\mathrm{T}_{4}}$ treatment before screening, and hence, they were excluded from the judgment as to whether the screening results were positive or negative as they had already been diagnosed with $\mathrm{CH}-\mathrm{C}$. Patients in group I were significantly identified more frequently through the screening program than those in group M: $88 \%$ (7/8) vs 29\% (4/14), $P<0.01$.

Out of the $24 \mathrm{CH}-\mathrm{C}$ patients, for 22 patients the filter paper assay for $\mathrm{FT}_{4}$ showed clear positive or negative results during screening (Fig. 4). The remaining two patients had been started on $\mathrm{L}^{-} \mathrm{T}_{4}$ therapy before screening. Because no blood samples were collected from any patient between 8 and 11 days of age, $\mathrm{FT}_{4}$ measurements were arbitrarily divided into those obtained on or before 10 days of age $\left(\mathrm{FT}_{4}\right.$ before $10 \mathrm{D}$, $n=18$, collected from 18 patients) and those obtained on or after 11 days of age $\left(\mathrm{FT}_{4}\right.$ after $11 \mathrm{D}, n=16$, collected from 14 patients). Overall, the $\mathrm{FT}_{4}$ level before $10 \mathrm{D}$ was $0.82 \pm 0.56 \mathrm{ng} / \mathrm{dl}$ (median, 5 days of age; range, 4-7 days), whereas the $\mathrm{FT}_{4}$ level after 11D was $0.57 \pm 0.13 \mathrm{ng} / \mathrm{dl}$ (median, 17.5 days; range, 12-31 days; Fig. 4). In addition, when we analyzed the data exclusively obtained from patients whose $\mathrm{FT}_{4}$ levels had been determined twice $(n=10)$, no significant difference was observed between $\mathrm{FT}_{4}$ before $10 \mathrm{D}(0.46 \pm 0.05 \mathrm{ng} / \mathrm{dl})$ and $\mathrm{FT}_{4}$ after $11 \mathrm{D}$ $(0.52 \pm 0.02 \mathrm{ng} / \mathrm{dl})$. Thus, $\mathrm{FT}_{4}$ values in $\mathrm{CH}-\mathrm{C}$ patients appeared to be stable during the neonatal period. A comparison of $\mathrm{FT}_{4}$ levels in group $\mathrm{M}(n=17)$ with those in group I $(n=15)$ also did not show a statistically significant difference (group M, $0.81 \pm 0.49 \mathrm{ng} / \mathrm{dl}$; group I, $0.60 \pm 0.37 \mathrm{ng} / \mathrm{dl})$, indicating that the severity of hypothyroidism did not differ significantly between these two groups, differentiated by pituitary involvement.

Evaluation of the performance of the screening system is depicted in Table 3. Our screening system yielded 13 true positives and nine false negatives, so that the sensitivity of detection of a true positive was calculated to be 59.1\%. Specificity and PPVs were calculated to be 99.99 and $11.5 \%$ respectively. A total of 740003 newborns were screened during the study period and 113 newborns were sent for thorough evaluation based on two consecutive $\mathrm{FT}_{4}$ measurements. The cutoff level used was $0.7 \mathrm{ng} / \mathrm{dl}$ serum $(9.0 \mathrm{pmol} / \mathrm{l})$. In the next step, we simulated the performance of the screening system with higher cutoff values. As depicted in Fig. 4, $\mathrm{FT}_{4}$ levels for nine patients who were not identified in the screening ranged from 0.81 to $2.02 \mathrm{ng} / \mathrm{dl}$ (median, $0.9 \mathrm{ng} / \mathrm{dl}$ ), which was substantially lower than the reference range of 


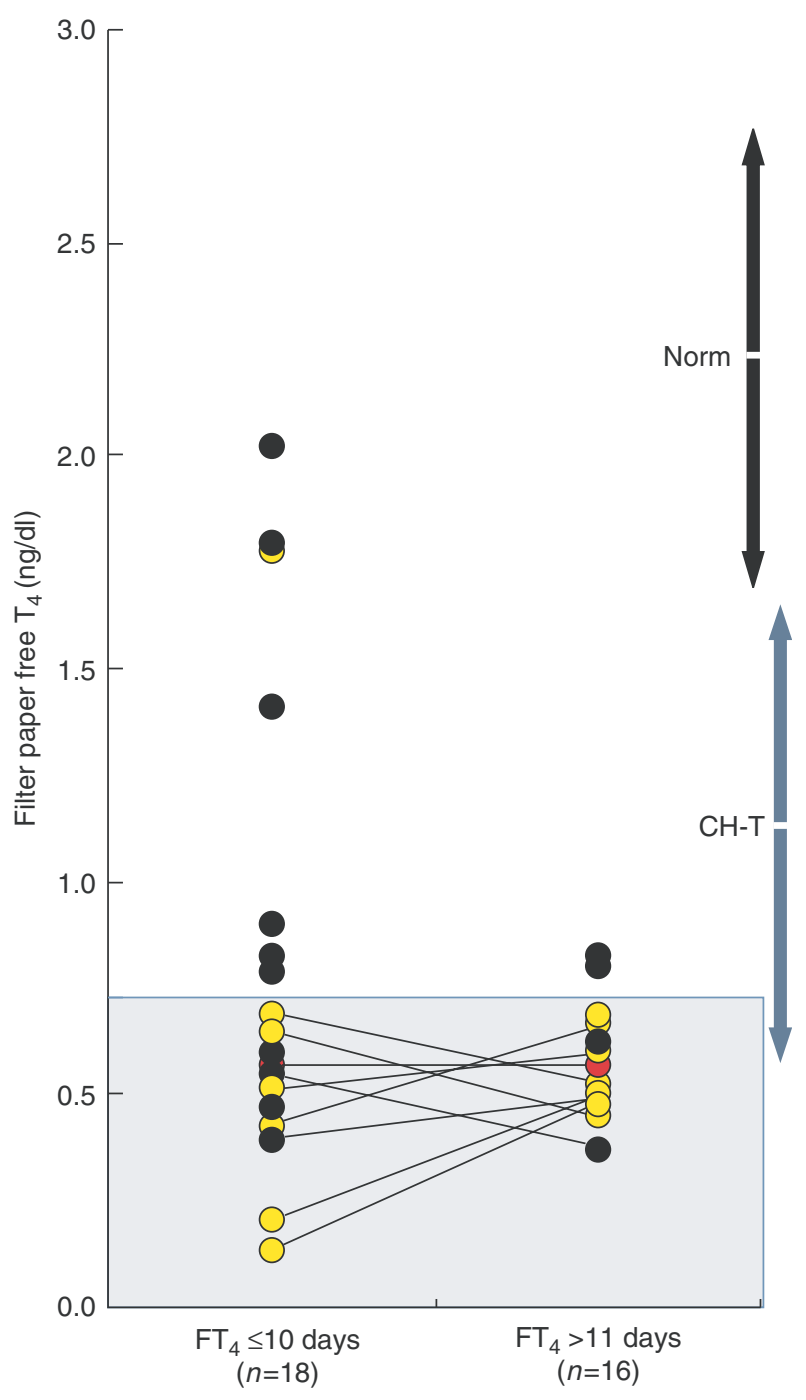

Figure 4 Distribution of $\mathrm{FT}_{4}$ values from the filter paper assay for 22 patients with $\mathrm{CH}-\mathrm{C}$. $\mathrm{FT}_{4}$ measurements obtained before 10 days of age ( $\mathrm{FT}_{4}$ before 10D) and those obtained after 11 days $\left(\mathrm{FT}_{4}\right.$ after 11D) did not differ significantly. The black circles indicate $\mathrm{FT}_{4}$ obtained from patients in group $\mathrm{M}$ (with multiple pituitary hormone deficiencies), the yellow circles indicate $\mathrm{FT}_{4}$ obtained from patients in group I (isolated hypothyroidism), and the red circles indicate $\mathrm{FT}_{4}$ obtained from patient 24 . The shaded area indicates $\mathrm{FT}_{4}$ values below the cutoff of $0.7 \mathrm{ng} / \mathrm{dl}$. Determinants from the same individuals are connected by solid lines. The black arrow (norm) indicates the mean \pm 1 s.D. $(2.22 \pm 0.58 \mathrm{ng} / \mathrm{dl})$ of $\mathrm{FT}_{4}$ values from the filter paper assay conducted on 67933 normal newborns. The blue arrow $(\mathrm{CH}-\mathrm{T})$ indicates the mean \pm 1 s.D. $(1.08 \pm 0.54 \mathrm{ng} / \mathrm{dl})$ of $\mathrm{FT}_{4}$ values from filter paper assay on 61 patients diagnosed with $\mathrm{CH}-\mathrm{T}$.

$1.64-2.80 \mathrm{ng} / \mathrm{dl}$ (21.1-36.0 pmol/l; data obtained from the 67933 normal newborns). If the cutoff value is raised to $0.9 \mathrm{ng} / \mathrm{dl}$ serum $(11.6 \mathrm{pmol} / \mathrm{l})$, then an additional five patients would have been found to be positive by the screening, and the estimated sensitivity would be increased by $81.8 \%$.

\section{Discussion}

In Japan, two types of ELISA-based kits are available for measuring $\mathrm{FT}_{4}$ levels in dried blood samples on filter paper; one developed by Siemens Healthcare Diagnostics K.K and another by Eiken Chemical Co. Ltd. Because $\mathrm{TSH}$ and $\mathrm{FT}_{4}$ can be measured with a common detection module, additional costs for $\mathrm{FT}_{4}$ measurements are only those incurred for reagents: 465 yen for TSH alone vs 705 yen for TSH and $\mathrm{FT}_{4}$ determination per newborn examined. Most of the screening centers adopt a primary TSH and backup $\mathrm{FT}_{4}$ system: the filter paper method is used for measuring TSH in all newborns, while it is used for measuring $\mathrm{FT}_{4}$ only in those with high TSH values for confirmation of possible hypothyroidism $(11,12)$. To detect $\mathrm{CH}-\mathrm{C}$, certain areas, including Kanagawa prefecture and Sapporo city, have adopted a combined primary TSH-FT 4 screening system $(7,9)$. After the report from Sapporo city (7), this report is the second audit of this $\mathrm{CH}-\mathrm{C}$ newborn screening system, conducted on a larger population and for a longer study period. We also tried to trace $\mathrm{CH}-\mathrm{C}$ patients not identified by neonatal screening (false-negative cases).

The ELISA-based filter paper $\mathrm{FT}_{4}$ kits are almost exclusively used in Japan. One may argue against its accuracy in determining $\mathrm{FT}_{4}$ levels, considering that some TBG-deficient patients were falsely detected to have low $\mathrm{FT}_{4}$ levels and that the equilibrium dialysis method is the gold standard $(15,16)$. However, it has been difficult to introduce the equilibrium dialysis method in newborn screening because it requires a larger volume serum sample and longer measurement times. On the other hand, to use the $\mathrm{FT}_{4}$ index instead of $\mathrm{FT}_{4}$, tri-iodothyronine $\left(\mathrm{T}_{3}\right)$ uptake must also be measured, which increases cost. $\mathrm{FT}_{4}$ determined by ELISA on filter paper blood samples seems to correctly reflect $\mathrm{FT}_{4}$ status in newborns because most $(88 \%) \mathrm{FT}_{4}$ values in $\mathrm{CH}-\mathrm{C}$ patients were more than 2 s.D. below the mean of normal newborns and because $\mathrm{FT}_{4}$ levels in $\mathrm{CH}-\mathrm{T}$ were distributed in a substantially low range (0.04-2.32 ng/dl; Fig. 4). Moreover, Fig. 4 shows that the $\mathrm{FT}_{4}$ levels measured using the filter paper method may be consistent even at lower concentrations of $\mathrm{FT}_{4}$. Thus, we believe that although $\mathrm{FT}_{4}$ levels determined using the filter paper samples may not be identical to those measured by the equilibrium dialysis method, the assay is a promising, practical alternative for use in $\mathrm{CH}-\mathrm{C}$ screening. Because combined $\mathrm{TSH}_{-} \mathrm{T}_{4}$ is recommended as the ideal strategy for detecting both $\mathrm{CH}-\mathrm{C}$ and $\mathrm{CH}-\mathrm{T}$ by the American Thyroid Association and Pediatric Endocrine Societies in the US and Europe (2), we think it is justified to continue implementation of our combined $\mathrm{TSH}-\mathrm{FT}_{4}$ system as a new version of the TSH- $\mathrm{T}_{4}$ system.

From our survey, the incidence of $\mathrm{CH}-\mathrm{C}$ was calculated as 1 in 30833 live births, while that of $\mathrm{CH}-\mathrm{T}$ was 1 in 3472 live births. Thus, the $\mathrm{CH}-\mathrm{T} / \mathrm{CH}-\mathrm{C}$ ratio in this study was 8.9 , which is close to the ratio 8.4 reported from 


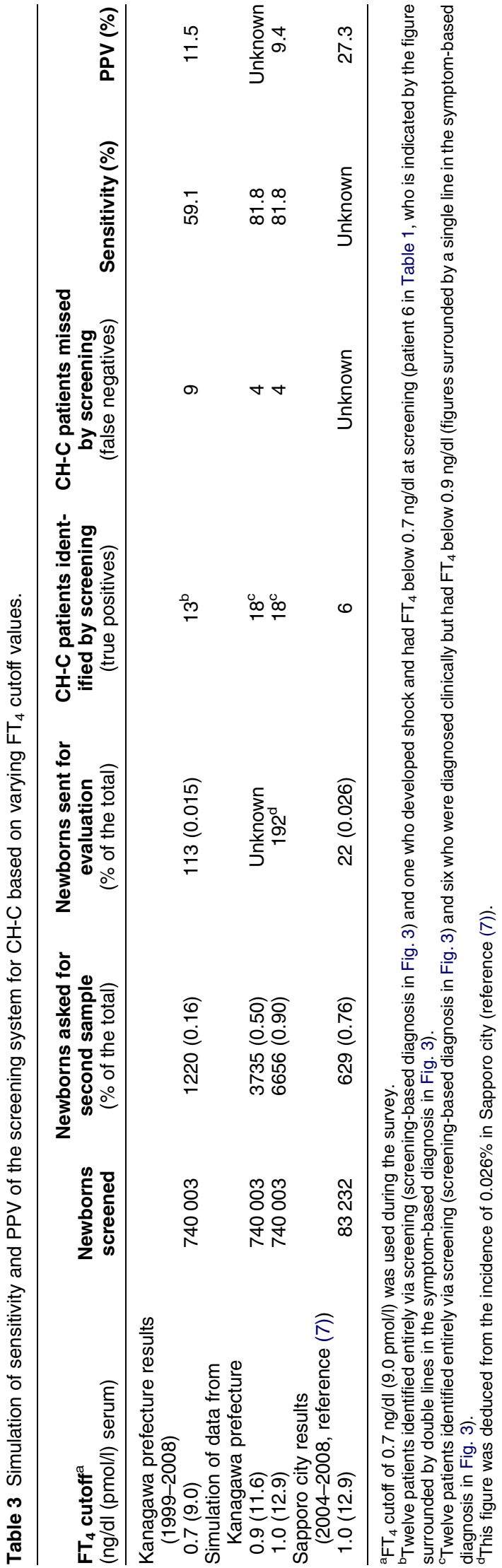

The Netherlands (6). Although we previously reported a much lower $\mathrm{CH}-\mathrm{C}$ incidence (1 in 160516 births) (9), that survey was based on only the cases detected through screening. The incidence rate of 1 in 30833 reported here is likely to be underestimated because this study was based on a questionnaire survey and falsenegative cases may not have been recorded. Indeed, we could not obtain follow up data on 11 cases identified in the preliminary survey, as well as on eight patients with positive screening results. In addition, because correct diagnosis of $\mathrm{CH}-\mathrm{C}$ is difficult $(17,18)$, especially in those with isolated hypothyroidism, some cases may have been overlooked. Moreover, as shown in Fig. 4, the mean values and range of $\mathrm{FT}_{4}$ in $\mathrm{CH}-\mathrm{C}$ patients were lower than those in $\mathrm{CH}-\mathrm{T}$ patients, suggesting that milder forms of $\mathrm{CH}-\mathrm{C}$ may escape detection.

A remarkable finding in this study is that isolated hypothyroidism (group I) was detected in one-third of the total $\mathrm{CH}-\mathrm{C}$ population. Previous studies have found that $78 \%$ (5) to $98 \%$ (8) of CH-C patients had multiple pituitary hormone defects such as septo-optic dysplasia. There are some explanations for this discrepancy. First, isolated $\mathrm{CH}-\mathrm{C}$ patients present less prominent symptoms than those with multiple pituitary hormone deficiencies $(19,20,21,22)$ and hence may be missed in the absence of screening. Indeed, all but one patient in group I was identified through the newborn screening. A Dutch screening system with TSH, $\mathrm{T}_{4}$, and TBG determination (5) reported a prevalence rate of $22 \%$ of isolated $\mathrm{CH}-\mathrm{C}$, which is closer to our findings. Secondly, ethnic differences may be a factor: in Sapporo city, two of six $\mathrm{CH}-\mathrm{C}$ patients were reported to demonstrate isolated hypothyroidism (7). Thirdly, some patients may not have been correctly diagnosed: a patient (patient 21 in Table 2) with pituitary hypoplasia is likely to have other hormone deficiencies. Finally, transient hypothyroidism may not be definitively ruled out, especially in younger patients. However, the authors are aware of a patient in group I (patient 15) who demonstrated severe hypothyroidism when $\mathrm{L}_{-} \mathrm{T}_{4}$ therapy was tentatively interrupted. Reevaluation of all other patients in group I will determine the true incidence of isolated hypothyroidism.

Our current system yielded a sensitivity of $59.1 \%$ and PPV of $11.0 \%$ in detecting $\mathrm{CH}-\mathrm{C}$. In fact, 12 patients were diagnosed with $\mathrm{CH}-\mathrm{C}$ entirely on the basis of low $\mathrm{FT}_{4}$ levels at newborn screening. Above all, the presence of four patients in group $\mathrm{M}$, who were overlooked clinically but in whom low $\mathrm{FT}_{4}$ levels were detected at screening, underscores the usefulness of our combined primary $\mathrm{TSH}^{-\mathrm{FT}_{4}}$ system. The sensitivity of $59.1 \%$ seems superior to the reported sensitivity of $19.0 \%$ in the state of Indiana, USA, where $\mathrm{T}_{4}$ measurement was used (8). On the other hand, a study from The Netherlands reported the sensitivity to be $71.4 \%$ (6). Because our study relied on responses to a questionnaire, the actual sensitivity of our screening system may be lower: physicians who did not respond may have 
$\mathrm{CH}-\mathrm{C}$ patients who were missed in the screening, some unrecognized cases with isolated hypothyroidism may be present, and early death of patients with multiple pituitary hormone deficiencies may have been ignored. Thus, we cannot directly compare the performance of our system to that used in The Netherlands.

Setting a higher cutoff for $\mathrm{FT}_{4}$ has both advantages and disadvantages. At a cutoff of $0.9 \mathrm{ng} / \mathrm{dl}$ instead of $0.7 \mathrm{ng} / \mathrm{dl}$, the estimated sensitivity rises to $81.8 \%$; it may increase three times more considering the requests for a second filter paper test (retesting ratio, $0.50 \%$ ). In Sapporo city, the $\mathrm{FT}_{4}$ cutoff has been set to $1.0 \mathrm{ng} / \mathrm{dl}(7)$; six $\mathrm{CH}-\mathrm{C}$ patients were identified through the screening over 4 years, and the prevalence of $\mathrm{CH}-\mathrm{C}$ was reported to be 1 in 13872 live births (Table 3). If a cutoff of $0.7 \mathrm{ng} / \mathrm{dl}$ were to be applied to their cohort, only one of six CH-C patients would have been detected by screening. Thus, resetting the cutoff value to $0.9 \mathrm{ng} / \mathrm{dl}$ (or higher) may be necessary. This level is in accordance with the $\mathrm{FT}_{4}$ cutoff $0.93 \mathrm{ng} / \mathrm{dl}$ used in The Netherlands for the diagnosis of $\mathrm{CH}-\mathrm{C}(5)$ and is $\sim-2$ s.D. of both the reported cord blood values (23) and our $\mathrm{FT}_{4}$ values (Fig. 3) for normal newborns.

Adequacy of the retesting ratio depends on many factors including population size, system performance parameters such as sensitivity and PPV, and local economic conditions. The retesting ratio was as high as $0.76 \%$ in Sapporo city, due to a higher cutoff value and inclusion of low-birth weight newborns. This ratio may be acceptable in a smaller city but may not be suitable for Kanagawa prefecture. The estimated retesting ratio of $0.50 \%$ (3735 samples during 10 years) resulting from a cutoff of $0.9 \mathrm{ng} / \mathrm{dl}$ may be more acceptable than a ratio of $0.76 \%$. A comparative figure for retesting for congenital adrenal hyperplasia in Kanagawa prefecture is $0.3 \%$. Because $\mathrm{FT}_{4}$ determinants did not change significantly according to collection dates (Fig. 4), as shown also in normal newborns (13), differential cutoff values according to the sampling dates are not expected to reduce the retesting ratio.

Another problem is the introduction of an immediate evaluation system to facilitate early treatment of $\mathrm{CH}-\mathrm{C}$ patients, especially for those with multiple pituitary hormone deficiencies. As stated in the Subjects and methods section, unless two consecutive tests reveal low $\mathrm{FT}_{4}$ values, newborns will not be subject to a thorough evaluation in our system. The aim of performing a second sampling is to exclude false positives. Indeed, during the study period, second samples were requested for 1220 newborns, but only 113 of these newborns were sent for thorough evaluation and 1107 falsepositive cases were eliminated (Table 3). Even with a cutoff of $1.0 \mathrm{ng} / \mathrm{dl}$, the number of newborns sent for evaluation will increase minimally ( 79 additional cases across 10 years). We retrospectively analyzed the impact of introduction of an immediate evaluation system in which newborns with $\mathrm{FT}_{4}$ lower than $0.5 \mathrm{ng} / \mathrm{dl}(6.4 \mathrm{pmol} / \mathrm{l})$ will be immediately evaluated.
Seven $\mathrm{CH}-\mathrm{C}$ patients, including three patients in group $\mathrm{M}$, would have been diagnosed without delay. However, according to our simulation, this strategy will create a false-positive number of more than 200 over 10 years, with a PPV of $2.8 \%$. The question of whether this figure is reasonable is beyond the scope of our study. Nevertheless, we plan to improve our screening strategy by considering scientific, economical, ethical, and political issues.

In conclusion, measurement of $\mathrm{FT}_{4}$ in dried blood spots on filter paper is suitable for newborn screening for $\mathrm{CH}-\mathrm{C}$; moreover, the combined primary $\mathrm{TSH}-\mathrm{FT}_{4}$ system applied in Kanagawa prefecture identified a significant number of $\mathrm{CH}-\mathrm{C}$ patients before they manifested clinical symptoms. The survey identified $24 \mathrm{CH}-\mathrm{C}$ patients, 14 of whom had multiple pituitary hormone deficiencies, yielding an incidence rate of $\mathrm{CH}-\mathrm{C}$ of 1 in 30833 live births. Screening sensitivity was calculated to be $59.1 \%$, based on 13 true-positive cases and nine false-negative cases, with a cutoff of $0.7 \mathrm{ng} / \mathrm{dl}$ of $\mathrm{FT}_{4}$. A more appropriate (higher) $\mathrm{FT}_{4}$ cutoff value and proper implementation of the screening would facilitate early detection of $\mathrm{CH}-\mathrm{C}$ cases.

\section{Declaration of interest}

The authors declare that there is no conflict of interest that could be perceived as prejudicing the impartiality of the research reported.

\section{Funding}

This research did not receive any specific grant from any funding agency in the public, commercial or not-for-profit sector.

\section{Author contribution statement}

M Adachi, Y Yamagami, and F Hirahara conceptualized and designed the study. M Adachi and A Soneda contributed to the data collection, analysis, and writing of the manuscript. Y Asakura and K Muroya contributed to preparation of the manuscript by critically analyzing it.

\section{Acknowledgements}

The authors wish to thank all the pediatric doctors who participated in the survey. In addition, the authors are grateful to Ms Kumiko Kagiya for her assistance with data handling. Finally, they wish to thank Mr Masaru Fukushi (Sapporo Immuno Diagnostic Laboratory, Sapporo, Japan) for his invaluable advice in preparing the manuscript.

\section{References}

1 Büyükgebiz A. Newborn screening for congenital hypothyroidism. Journal of Pediatric Endocrinology \& Metabolism 200619 1291-1298. (doi:10.1515/JPEM.2006.19.11.1291)

2 American Academy of Pediatrics, Rose SR; Section on Endocrinology and Committee on Genetics, American Thyroid Association, Brown RS; Public Health Committee, Lawson Wilkins Pediatric Endocrine Society, Foley T, Kaplowitz PB, Kaye CI, Sundararajan S \& Varma SK. Update of newborn screening and therapy for congenital hypothyroidism. Pediatrics 2006117 2290-2303. (doi:10.1542/peds.2006-0915) 
3 Hanna CE, Krainz PL, Skeels MR, Miyahira RS, Sesser DE \& LaFranchi SH. Detection of congenital hypopituitary hypothyroidism: ten-year experience in the Northwest Regional Screening Program. Journal of Pediatrics 1986109 959-964. (doi:10.1016/ S0022-3476(86)80276-1)

4 Hunter MK, Mandel SH, Sesser DE, Miyabira RS, Rien L, Skeels MR \& LaFranchi SH. Follow-up of newborns with low thyroxine and nonelevated thyroid-stimulating hormone-screening concentrations: results of the 20-year experience in the Northwest Regional Newborn Screening Program. Journal of Pediatrics 1998 132 70-74. (doi:10.1016/SO022-3476(98)70487-1)

5 van Tijn DA, de Vijlder JJ, Verbeeten B Jr, Verkerk PH \& Vulsma T. Neonatal detection of congenital hypothyroidism of central origin. Journal of Clinical Endocrinology and Metabolism 2005903350 3359. (doi:10.1210/jc.2004-2444)

6 Kempers MJ, Lanting CI, van Heijst AF, van Trotsenburg AS, Wiedijk BM, de Vijlder JJ \& Vulsma T. Neonatal screening for congenital hypothyroidism based on thyroxine, thyrotropin, and thyroxine-binding globulin measurement: potentials and pitfalls. Journal of Clinical Endocrinology and Metabolism 2006913370 3376. (doi:10.1210/jc.2006-0058)

7 Fujiwara F, Fujikura K, Okuhara K, Tsubaki J, Fukushi M, Fujita K, Fujieda K \& Tajima T. Central congenital hypothyroidism detected by neonatal screening in Sapporo, Japan (2000-2004): it's prevalence and clinical characteristics. Clinical Pediatric Endocrinology 200817 65-69. (doi:10.1297/cpe.17.65)

8 Nebesio TD, McKenna MP, Nabhan ZM \& Eugster EA. Newborn screening results in children with central hypothyroidism. Journal of Pediatrics 2010156 990-993. (doi:10.1016/j.jpeds. 2009.12.011)

9 Asakura Y, Tachibana K, Adachi M, Suwa S \& Yamagami Y. Hypothalamo-pituitary hypothyroidism detected by neonatal screening for congenital hypothyroidism using measurement of thyroid-stimulating hormone and thyroxine. Acta Paediatrica 2002 91 172-177. (doi:10.1080/080352502317285171)

10 LaFranchi S. Congenital hypothyroidism: etiologies, diagnosis, and management. Thyroid 19999 735-740. (doi:10.1089/thy.1999. 9.735)

$11 \mathrm{Gu}$ YH, Kato T, Harada S, Inomata H, Saito T \& Aoki K. Seasonality in the incidence of congenital hypothyroidism in Japan: gender-specific patterns and correlation with temperature. Thyroid 200717 869-874. (doi:10.1089/thy.2006.0317)

12 Nagasaki K, Asami T, Ogawa Y, Kikuchi T \& Uchiyama M. A study of the etiology of congenital hypothyroidism in the Niigata prefecture of Japan in patients born between 1989 and 2005 and evaluated at ages 5-19. Thyroid 2011 21 361-365. (doi:10. 1089/thy.2010.0005)

13 Gruñeiro-Papendieck L, Prieto L, Chiesa A, Bengolea S, Bossi G \& Bergadá C. Usefulness of thyroxine and free thyroxine filter paper measurements in neonatal screening for congenital hypothyroidism of preterm babies. Journal of Medical Screening 20007 78-81. (doi:10.1136/jms.7.2.78)
14 Fukushi M, Mashimo Y, Mizushima Y, Arai O, Kikuchi Y, Takasugi N, Fujieda K \& Matsuura N. Examination of enzaplate, $\mathrm{N}-\mathrm{FT}_{4}$ and its application for neonatal thyroid screening. Clinical Endocrinology 199038 1039-1042.

15 Nelson JC \& Tomei RT. Direct determination of free thyroxin in undiluted serum by equilibrium dialysis/radioimmunoassay. Clinical Chemistry 198834 1737-1744.

16 Deming DD, Rabin CW, Hopper AO, Peverini RL, Vyhmeister NR \& Nelson JC. Direct equilibrium dialysis compared with two non-dialysis free T4 methods in premature infants. Journal of Pediatrics 2007151 404-408. (doi:10.1016/j.jpeds.2007.03.046)

17 Mehta A, Hindmarsh PC, Stanhope RG, Brain CE, Preece MA \& Dattani MT. Is the thyrotropin-releasing hormone test necessary in the diagnosis of central hypothyroidism in children. Journal of Clinical Endocrinology and Metabolism $2003 \mathbf{8 8} 5696-5703$. (doi:10.1210/jc.2003-030943)

18 Faglia G, Bitensky L, Pinchera A, Ferrari C, Paracchi A, Beck-Peccoz P, Ambrosi B \& Spada A. Thyrotropin secretion in patients with central hypothyroidism: evidence for reduced biological activity of immunoreactive thyrotropin. Journal of Clinical Endocrinology and Metabolism $1979 \quad \mathbf{4 8} 989-998$. (doi:10.1210/jcem-48-6-989)

19 Pittman JA Jr, Haigler ED Jr, Hershman JM \& Pittman CS. Hypothalamic hypothyroidism. New England Journal of Medicine 1971285 844-845. (doi:10.1056/NEJM197110072851508)

20 Niimi H, Inomata H, Sasaki N \& Nakajima H. Congenital isolated thyrotrophin releasing hormone deficiency. Archives of Disease in Childhood 198257 877-878. (doi:10.1136/adc.57.11.877)

21 Collu R, Tang J, Castagné J, Lagacé G, Masson N, Huot C, Deal C, Delvin E, Faccenda E, Eidne KA \& Van Vliet G. A novel mechanism for isolated central hypothyroidism: inactivating mutations in the thyrotropin-releasing hormone receptor gene. Journal of Clinical Endocrinology and Metabolism 199782 1561-1565. (doi:10. 1210/jc.82.5.1561)

22 Bonomi M, Busnelli M, Beck-Peccoz P, Costanzo D, Antonica F, Dolci C, Pilotta A, Buzi F \& Persani L. A family with complete resistance to thyrotropin-releasing hormone. New England Journal of Medicine $2009 \mathbf{3 6 0}$ 731-734. (doi:10.1056/ NEJMc0808557)

23 Williams FL, Simpson J, Delahunty C, Ogston SA, BongersSchokking JJ, Murphy N, van Toor H, Wu SY, Visser TJ, Hume R \& Collaboration from the Scottish Preterm Thyroid Group . Developmental trends in cord and postpartum serum thyroid hormones in preterm infants. Journal of Clinical Endocrinology and Metabolism 200489 5314-5320. (doi:10.1210/jc.2004-0869)

Received 26 July 2011

Revised version received 14 January 2012

Accepted 1 February 2012 